\title{
PERUBAHAN POLA RUANG DESA BALI AGA BELANDINGAN KINTAMANI, BALI
}

\author{
Ni G.A Diah Ambarwati Kardinal, I Komang Gede Santhyasa \\ Fakultas Teknik Universitas Hindu Indonesia, Bali, Indonesia \\ e-mail: diahkardinalpwkunhi@gmail.com / Telp.+62 81394079340
}

\begin{abstract}
Bali Aga Villages are also known to have unique settlement patterns in Bali. Each village has its own characteristics. Like those found in Bali Aga Belandingan Village, located in the Kintamani Mountains, Bangli. Its location in the mountains with steep topography influences its village settlement pattern so that the settlement pattern is different from other Balinese aga mountain villages both in the Kintamani region itself and when compared to the Balinese aga mountain villages in other districts such as Tigawasa or Sembiran. At present there is very little information about Belandingan village. Its status as 15 villages supporting the Geopark makes the community want to make Belandingan Village a Tourism Village. Without documentation accompanied by feares that planning will eliminate the uniqueness of Belandingan village as Bali Aga Village. Changes in the pattern of village space have occurred. Important searches are carried out to understand the current context of spatial patterns for future planning. The method used in finding changes in spatial patterns is by tracing the history of the village which is then evaluated for changes that occur so that it can be seen whether these changes have damaged the traditional village structure of Bali Aga or have no effect on the pattern of village space. From this evaluation, it can also be seen how the village community views the changes that occur.
\end{abstract}

Keywords: change, Village pattern, Bali Aga Village

\section{Pendahuluan}

Korn dalam Runa (2018) menyatakan bahwa secara garis besar desa-desa d Bali dapat dibedakan menjadi dua tipe, yaitu desa bali pegunungan (Bali Aga) dan desa bali dataran. Desa Bali pegunungan adalah desa yang lebih tua, kebanyakan terletak di pegunungan, jumlahnya lebih sedikit, tetapi memiliki variasi fisik lebih banyak dibandingkan dengan desa Bali dataran, serta masih banyak memperlihatkan ciri-ciri praHindu (Hindu-Bali). Desa Bali dataran adalah tipe desa yang lebih muda, kebanyakan terletak di daerah dataran Bali selatan dan banyak dipengaruhi oleh Hindu-Jawa (Majapahit).

Ciri-ciri fisik desa pegunungan yang menonjol adalah adanya ruang terbuka bersama (communal open space) membujur menurut arah kaja-kelod gunung-laut) membagi desa menjadi dua bagian. Ruang terbuka itu memakai perkerasan batu kali dan meninggi kearah pegunungan atau bukit (Parimin dalam Runa, 2018)

Belandingan adalah sebuah desa bali aga di pegunungan kintamani Bangli. Letaknya relative terpencil dan masih jarang dikunjungi oleh masyarakat. Informasi mengenai desa Belandingan terutama mengenai spasial dan arsitekturnya sulit untuk dijumpai. Tulisan mengenai Belandingan lebih banyak mengenai potensi pariwisata yang dimilikinya karena Desa Belandingan termasuk dalam 15 desa pendukung kawasan geopark batur berdasarkan Destination Management Organization (DMO) (Sukariyanto, 2015) . 15 desa tersebut antara lain Desa Batur utara, Desa Batur Selatan, Desa Batur Tengah, Desa Kintamani, Desa Pinggan Desa Songan A, Desa Songan B, Desa Kedisan, Desa Buahan, Desa Trunyan, Desa Suter, Desa Abang Songan, Desa Abang Batudinding, Desa Sukawana dan Desa Belandingan.

Keberadaan Desa Belandingan diperkirakan sejak zaman bali kuna, yaitu pada masa sebelum datangnya empu kuturan. Bentuk-bentuk rumah pada jaman tersebut berupa rumah-rumah sederhana yang disebut dengan kubu masih ada hingga sekarang. Pola permukimannya terbagi atas blokblok perumahan berdasarkan garis keturunan. Dibeberapa blok rumah tampak memiliki pelinggih dewa kembar, yakni pelinggih untuk anak yang dilahirkan kembar dalam keluarga tersebut. Pola desa menyerupai pola linear dimana jalan utama desa memanjang dari arah utara selatan yang merupakan pusat permukiman tradisional. Namun arah hadap rumah tidak langsung menghadap ke jalan utama melainkan ke jalan-jalan yang kecil yang ada didepan blok barulah didalam blok tersebut halaman menjadi satu dan tidak terdapat sekat pagar. Pola lingkungan berpola linier dengan lintasan-lintasan jalan yang membentuk pola lingkungan yang sesuai dengan transis lokasi kemiringan dan lereng-lereng alam. Selain kompleks desa induk juga terdapat rumah-rumah yang menyebar di daerah tegalan membentuk sub lingkungan

Pola permukiman saat ini telah banyak mengalami perubahan. Salah satu penyebabnya adalah bantuan dari pihak pemerintah melalui 
program bedah rumah. Penyebab yang lain adalah kemampuan masyarakat yang terbatas dalam melestarikan rumah tradisional karena biaya yang dihabiskan untuk rumah tradisional jauh lebih mahal dibandingkan dengan membangun rumah modern dari beton. Rumah-rumah asli banyak sudah dalam kondisi rusak dan belum tertangani. Perubahan-perubahan pada pola ruangnya tersebut perlu didokumentasikan untuk meningkatkan pemahaman mengenai pola ruang desa sehingga dapat menjadi dasar dalam melakukan perencaan desa wisata. Sangat mendesak untuk dilakukan pendokumentasian yang lengkap seleuruh aspek baik sosial, budaya, ekonomi, dan spatial agar tidak terlambat seperti yang terjadi di Desa Sukawana yang telah kehilangan rumah tradisionalnya.

\section{Metode Penelitian}

Penelitian ini termasuk dalam penelitian non eksperimen karena tidak dilakukan tindakantindakan tertentu yang diujikan untuk mendapatkan hasil-hasil tertentu. Metode penelitian yang digunakan adalah metode deskriptif eksploratif serta evaluatif. Dalam proses pengumpulan data penelitian dengan melakukan survey primer dan sekunder.

Untuk menganalisa pola perubahan ruang yang terjadi menggunakan pendekatan penelusuran sejarah dan dilakukan evaluasi terhadap perubahanperubahan yang terjadi. Perubahan-perubahan tersebut dapat digolongkan apakah perubahan tersebut telah merusak tatanan desa tradisonal Bali aga atau tidak memiliki pengaruh terhadap pola ruang desa. Dari evaluasi ini juga dapat dilihat bagaimana cara pandang masyarakat Desa Belandingan terhadap perubahan-perubahan yang terjadi

\section{Hasil Penelitian dan Pembahasan}

\section{Sejarah Desa Bali Aga Belandingan}

Desa Belandingan pada awalnya dipimpin oleh seorang dukuh bernama Penunjung Tutur. Stana (dipuja) beliau adalah di Pura dukuh sekarang. Dahulu Kala Desa Belandingan terdiri atas dua desa yakni desa Bala dan Tandingan yang dipimpin oleh Dukuh Penunjung Tutur. Saat itu penduduknya berjumlah 1700 warga dari 17 keturunan. Kondisi ini oleh masyaraka disebut dengan istilah sepa satus. Secara geografis lokasi desa pertama berada didaerah permukiman yang saat ini mengalami perkembangan dan yang satu lagi berada dibalik bukit atau di Pura Puseh Meneng. Dahulu terdapat 2 sumber mata air yaitu yang satu berada di Manik Muncar dan satu lagi berada di Sau dan kemudian pembagian sumber mata air inilah yang menjadi malapetaka dan menyebabkan ketegangan dua daerah tersebut. Kemudian pada saat itu, pemimpin desa ingin keadilan bagi rakyatnya maka dibuatlah aturan bahwa warga yang berada di wilayah permukiman sekarang diharuskan mengambil air di wilayah balik bukit, begitu pula sebaliknya, warga di balik bukit diharuskan mengambil air di wilayah permukiman sekarang

Namun hal ini menjadi polemik yang akhirnya menyebabkan terbunuhnya kepala desa oleh warga yang merasa tidak senang akan aturan yang dibuat oleh karena masih-masing desa telah merasa memiliki masing-masing sumber air. Akhirnya jumlah penduduk semakin sedikit hingga menjadi 7 jiwa karena adanya konflik dan lambat laut perkembangan warga bertambah yang dikarenakan para pendatang dari desa sekitar seperti desa Sukawana. Dan tersisa penglingsir sejumlah 17 orang termasuk dari 7 orang yang selamat. Perkembangan pertumbuhan penduduk inilah yang pada akhirnya menyebabkan 2 desa yaitu desa Bala dan Tandingan menjadi satu desa yakni desa Belandingan.

\section{Karakter Desa Bali Aga Belandingan}

Secara Administratif Desa Belandingan masuk ke dalam Kecamatan Kintamani Kabupaten Bangli, Provinsi Bali. Berjarak $67 \mathrm{Km}$ dari Kota Propinsi Bali yaitu Denpasar. Jarak dari Ibukota Kabupaten adalah $30 \mathrm{Km}$ dan jarak dari ibukota kecamatan adalah $5 \mathrm{Km}$. Batas Administrasi Desa Belandingan adalah sebagai berikut:

Sebelah Utara :Desa Tembok (Kabupaten Buleleng)

\section{Sebelah Selatan : Desa Songan A}

Sebelah Timur : Desa Songan B

Sebelah Barat : Desa Pinggan dan Desa Siakin

Jumlah penduduk Desa Belandingan 1116 orang dengan jumlah KK sebanyak 320 KK. Luas wilayah Desa Belandingan mencapai $\pm 2.022 \mathrm{Ha}$. Desa Belandingan berada pada ketinggian $\pm 1250 \mathrm{~m}$ diatas permukaan laut sehingga berhawa sejuk. Karena terletak di ketinggian, maka view dari desa kearah sekitarnya sangat indah. Mata pencaharian mayoritas penduduknya adalah petani sayuran, maka sangat umum menjumpai pemandangan kebun sayur di punggung perbukitan desa. Penggunaan Lahan eksisting di desa didominasi oleh hutan dan perkebunan sayuran. Hanya $1 \%$ dari luas total wilayahnya yang digunakan sebagai permukiman dan berada pada daerah yang relatif lebih landai dari daerah sekitarnya. Besarnya lahan yang berfungsi sebagai hutan dikarenakan kondisi geografis kawasan yang terjal sehingga sulit dijadikan lahan permukiman. 


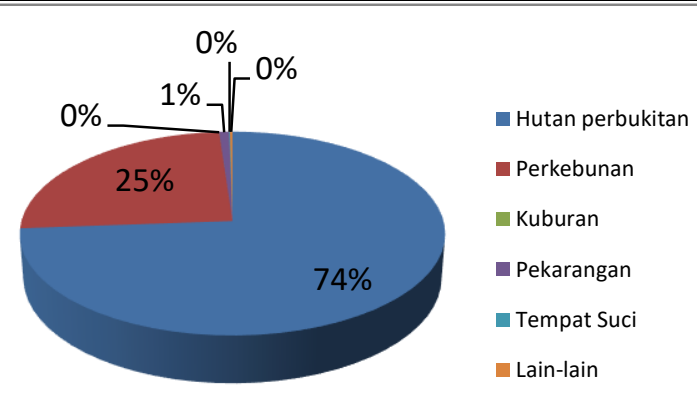

Gambar 1. Penggunaan Lahan di Desa Belandingan Sumber: Dokumentasi Pribadi 2017

\section{Pola Ruang Tradisional Desa Belandingan}

Menurut Dwijendra (2003) konsep ruang masyarakat Bali adalah harmoni dan religiusitas, dimana nilai-nilai religious merupakan hal utama. Dengan menggunakan konsep Bhuana Agung (Makrokosmos) dengan Bhuana Alit (Mikrokosmos) sebagai suatu pendekatan dalam tata ruang yang kemudian memberikan pengertian adanya jiwa dalam penataan ruang di Bali yang dikenal dengan konsep "Tri Hita Karana'. Selain itu ada beberapa konsep pokok lagi yang dituangkan dalam pengaturan ruang masyarakat Bali, 5 diantaranya:

1. Konsep Rwa Bhineda memberikan orientasi yang berlawanan seperti 'Luan-Teben (Hulu-Hilir), 'Kaja-Kelod' (Utara-Selatan) dan juga 'Sakral-profan' (Baik-Buruk)

2. Konsep Tri Angga memberikan orientasi vertical Utama-Madya-Nista

3. Konsep Nawa sanga memberikan kekuatan dan simbol pada struktur yang menggambarkan adanya pola struktur dan keterikatan antara komponen struktur,

4. Konsep Tri Mandala yang memberikan kekuatan orientasi horizontal UtamaMadya-Nista

5. Konsep dinamika, yaitu struktur dalam kebudayaan Bali yang berkaitan dengan ruang diartikan selain memiliki pola dan keteraturan , juga Memiliki sifat supel, luwes dan dinamis.

Perwujudan dari Konsepsi Tri Hita Karana di Desa Belandingan meliputi:

a. Palemahan (wilayah Desa) yaitu seluruh wilayah desa dengan sarana dan prasarana di dalamnya

b. Pawongan (manusia) yaitu keseluruhan dari masyarakat Desa Adat

c. Parahyangan (Tempat Ibadah), yaitu sarana peribadatan masyarakat Desa Belandingan

Letak dari Pura-pura di Desa Belandingan, tampaknya mengacu pada perbukitan di sisi utara dan timur desa. Pada Perbukitan disisi utara desa terdapat Pura Bale Agung, Pura Dukuh, Pura Manik Muncar dan Pura Batu Gede. Di perbukitan disisi timur desa terdapat pura Puseh. Bila melihat sebaran pura akan tampak dua kelompok pura yakni purapura yang berada di daerah tinggi (perbukitan) sebagai hulu yakni Pura Puseh, Pura Bale Agung, Pura Dukuh, Pura Manik Muncar dan Pura Batu Gede. Sedangkan pura yang berada di teben yakni Pura Dalem, Pura Penegtegan dan Pura Pemagpagan Tapi bila menilik fungsi dan lokasi dari ketiga pura tersebut menjadi wajar. Pura Dalem yang berdekatan dengan setra (kuburuan) menempati lokasi yang relatif datar. Demikian juga dengan Pura Penegtegan dan Pemagpagan yang berkaitan dengan fungsinya dengan kegiatan pertanian menempati lokasinya yang juga relative datar.

Hal unik lainnya mengenai letak Pura di Desa belandingan dimana salah satu pura milik Desa Belandingan terletak secara administratif di Desa Songan, tetapi lahan nya seluas $100 \mathrm{Ha}$ merupakan milik Desa Adat Belandingan yang sudah diwariskan oleh leluhur Desa. Demikian juga dengan Pura Batu Gede yang dimiliki oleh desa adat Belandingan, tetapi berada diwilayah perbatasan Desa Belandingan dengan Desa Songan.

Dari letak pura-pura, pemukiman dan setra dapat diidentifikasi zona Tri Mandala Desa Belandingan. Perbukitan di sisi utara dan timur desa menjadi zona utama dengan keberadaan Purapuranya yang memanjang di kaki bukit. Madya mandala dicirikan dengan keberadaan kawasan permukiman, dan nista mandala dicirikan dengan keberadaan setra.

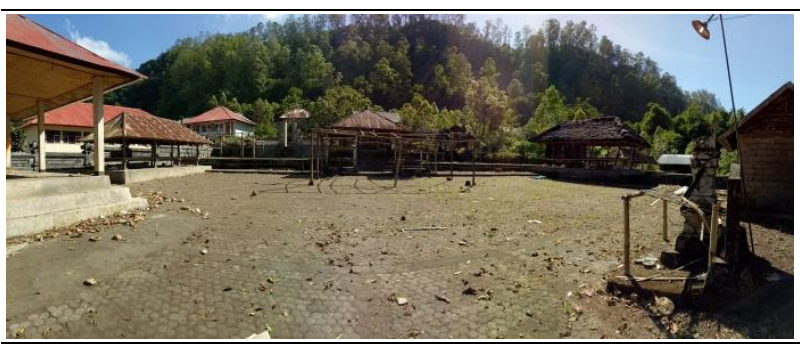

Gambar 2. Pura Desa Yang Ada di Bukit

Sumber: Dokumentasi Pribadi, 2017

Desa Belandingan terdiri atas satu desa dinas yang secara adat terbagi atas 12 banjaran. Istilah banjaran menjadi sangat unik karena bukanlah istilah yang umum. Masyarakat desa belandingan terdiri atas beberapa klan keluarga (soroh) yakni tangkas, Celagi Manis, Pasek Gelgel, Pasek kayu selem, Panji, Pasek Tangga, Kemoning dan Pande. Belandingan tidak mengenal adanya kasta.

Tabel 1 Pembagian Banjaran di Desa Belandingan

\begin{tabular}{|c|l|l|c|}
\hline No & $\begin{array}{l}\text { Nama } \\
\text { Banjaran/ } \\
\text { dadia }\end{array}$ & \multicolumn{1}{|c|}{ Soroh } & $\begin{array}{c}\text { Jumlah } \\
\text { KK }\end{array}$ \\
\hline $\mathbf{1}$ & $\begin{array}{l}\text { Kaja } \\
\text { Kangin }\end{array}$ & $\begin{array}{l}\text { Tangkas Kori } \\
\text { Agung }\end{array}$ & 10 \\
\cline { 3 - 4 } & $\begin{array}{l}\text { Celagi Manis } \\
\text { (Karangasem) }\end{array}$ & 50 \\
\cline { 3 - 4 } & Pasek Gel Gel & 40 \\
\hline
\end{tabular}


Ni G.A Diah Ambarwati Kardinal, I Komang Gede Santhyasa

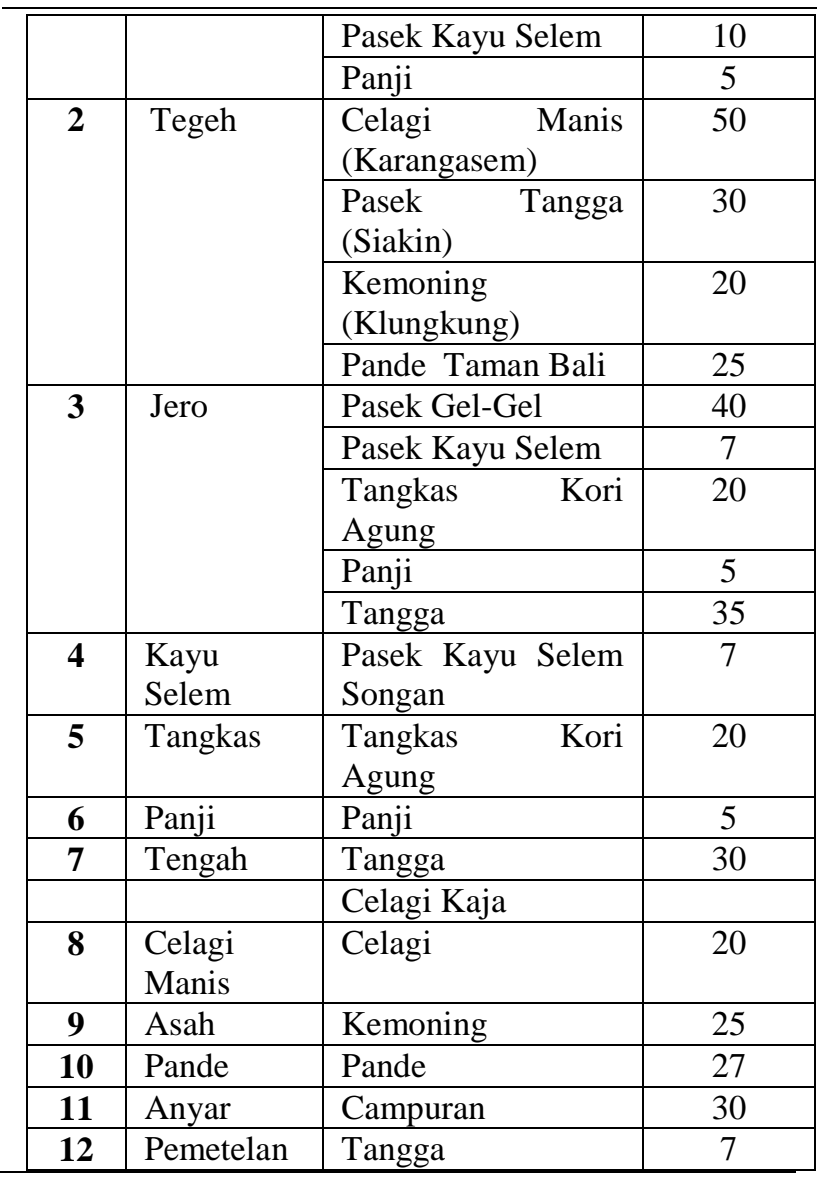

Sumber: wawancara, 2017

Permukiman di desa belandingan berpola linier mengikuti dua jalan utama dan terbagi atas blok-blok kecil /banjaran berdasarkan garis keturunan. Masih terdapat bukti pembagian blokblok permukiman tersebut berupa batas berbentuk batu yang tertanam di tanah. Pintu utama masuk ke pekarangan tidak langsung dari jalan utama, melainkan melalui gang kecil yang menjadi penghubungnya. Antra 1 keluarga dengan keluarga lainnya dalam satu blok banjaran tidak terdapat pagar pembatas. Bangunan tradisional di Desa Belandingan terdiri atas 1 massa bangunan yang masih dipertahankan dan saat ini terdapat massa bangunan tambahan. Dalam satu blok permukiman terdapat merajan keluarga dan pelinggih-pelinggih tambahan seperti pelinggih hyang kembar bila memiliki anak kembar ataupun hyang manik mas bila ada perempuan yang mengalami keguguran. Letak merajan dari keluarga/dadya bersebelahan dengan jalan. Tampaknya posisi bersebelahan dengan jalan ini dipilih karena kondisi geografisnya dimana dibagian belakang permukiman kondisinya menurun. Jadi posisi merajan menempati posisi tertinggi dari blok permukiman dadya tersebut. Satu bangunan tradisional di Belandingan memiliki fungsi yang lengkap yakni untuk ibadah, dapur dan tidur. Variasi susunan ruang dalam biasanya hanya pada posisi Dapur dan Bale (Dalam gambar di tunjukkan oleh Keterangan A dan D).
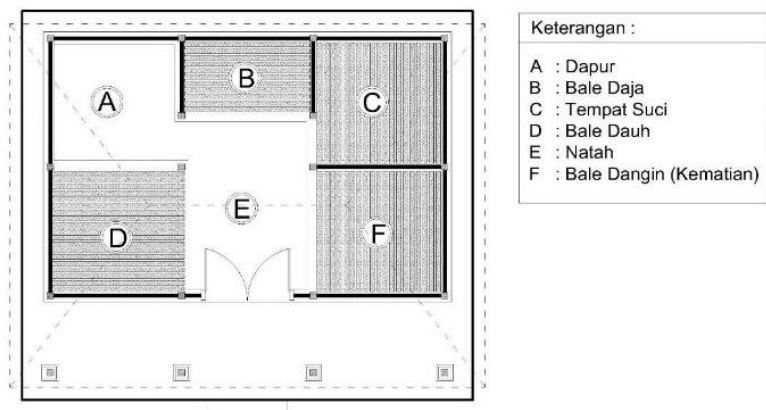

\section{Gambar 4. Penggunaan Lahan di Desa Belandingan}

Sumber: Dokumentasi Pribadi 2017

Gambar 3. Peta Pembagian Banjaran di Desa Belandingan

Sumber: Dokumentasi Pribadi, 2017 

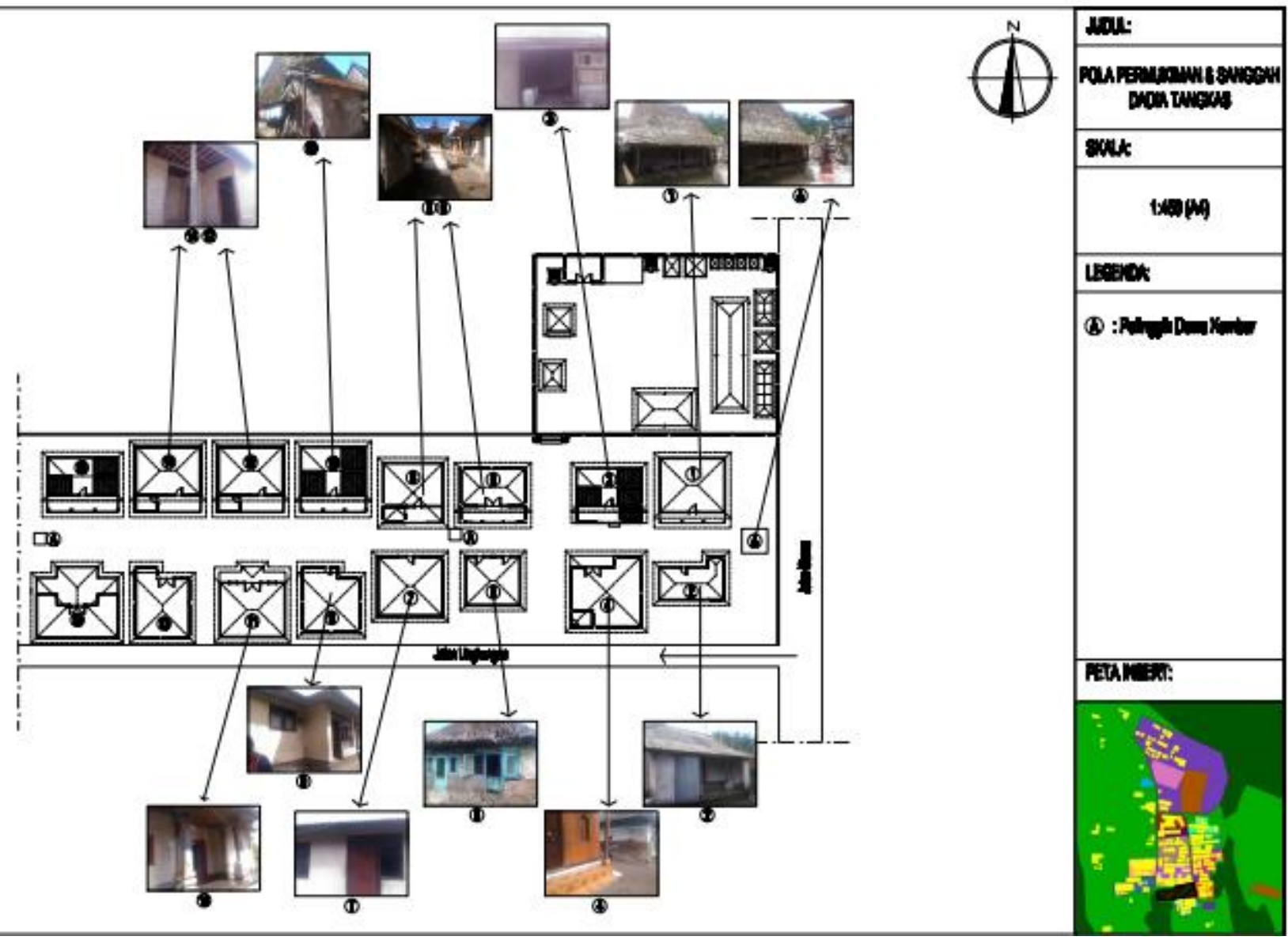

Gambar 5. Pola Permukiman Trradisional Belandingan pada Banjaran Tangkas Sumber: Dokumentasi Pribadi,2017

\section{Perubahan Pola Ruang Desa Belandingan}

Pada skala makro Desa, Perubahan utama yang terjadi di Desa Belandingan adalah perpindahan pusat permukiman dari sekitar Pura Puseh Meneng ke Pusat Permukiman yang ada sekarang. Alasan perpindahan tersebut tidak diketahui demikian juga dengan waktu perpindahannya. Perpindahan permukiman dari Pura Puseh meneng ke pusat permukiman yang sekarang tidak serta merta membuat masyarakat memindahkan lokasi pura puseh tersebut. Masyarakat tidak berani memindahkan pura-pura yang sudah ada, walaupun jarak tempuh masyarakat ke pura-pura tersebut mejadi cukup jauh. Perubahan kedua yang cukup besar mempengaruhi pola ruang Desa Belandingan adalah pemekaran wilayah permukiman yakni di banjaran anyar yang memanfaatkan laba (tanah milik) Pura Bale Agung. Seiring pemekaran permukiman dengan bertambahnya penduduk menjadikan bangunan-bangunan kubu di tegalan milik warga desa berubah dari bangunan non permanen menjadi bangunan permanen. Mereka pulang ke rumah tua saat-saat upacara di desa dan keluarga. Fasilitas-fasilitas kawasan pun bertambah seperti penyediaan sarana sekolah dasar, puskesmas pembantu, pos linmas dan wantilan.

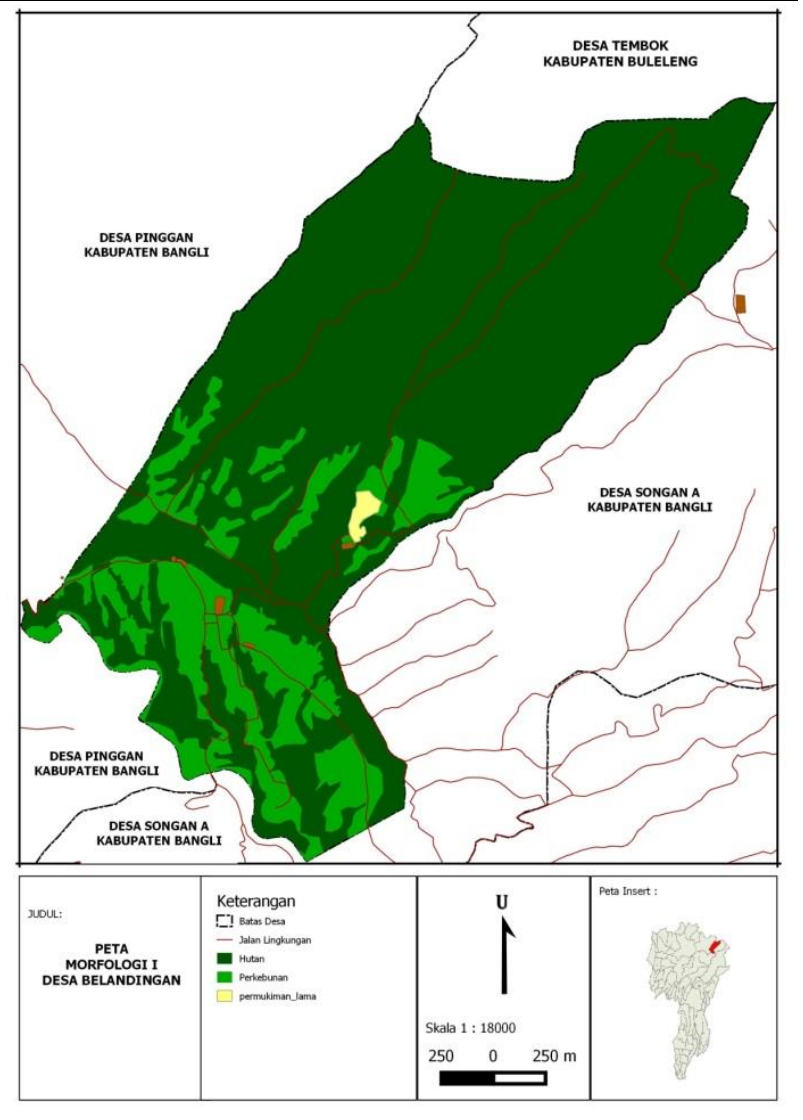

Gambar 6. Morfologi Ruang Desa Belandingan Kawasan Permukiman Berada di Sekitar Pura Puseh Meneng

Sumber: Analisis, 2017 
Ni G.A Diah Ambarwati Kardinal, I Komang Gede Santhyasa

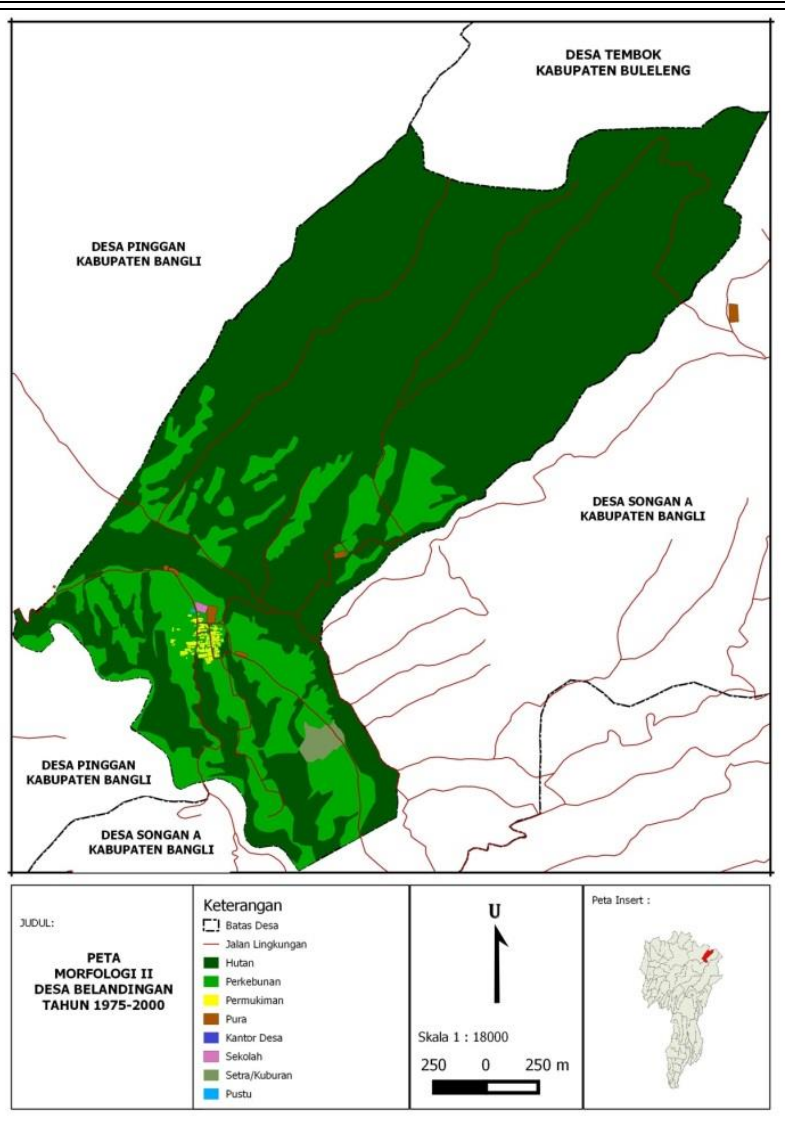

Gambar 7. Morfologi Kedua Desa Belandingan Tahun 1975-2000

Sumber: Analisis, 2017

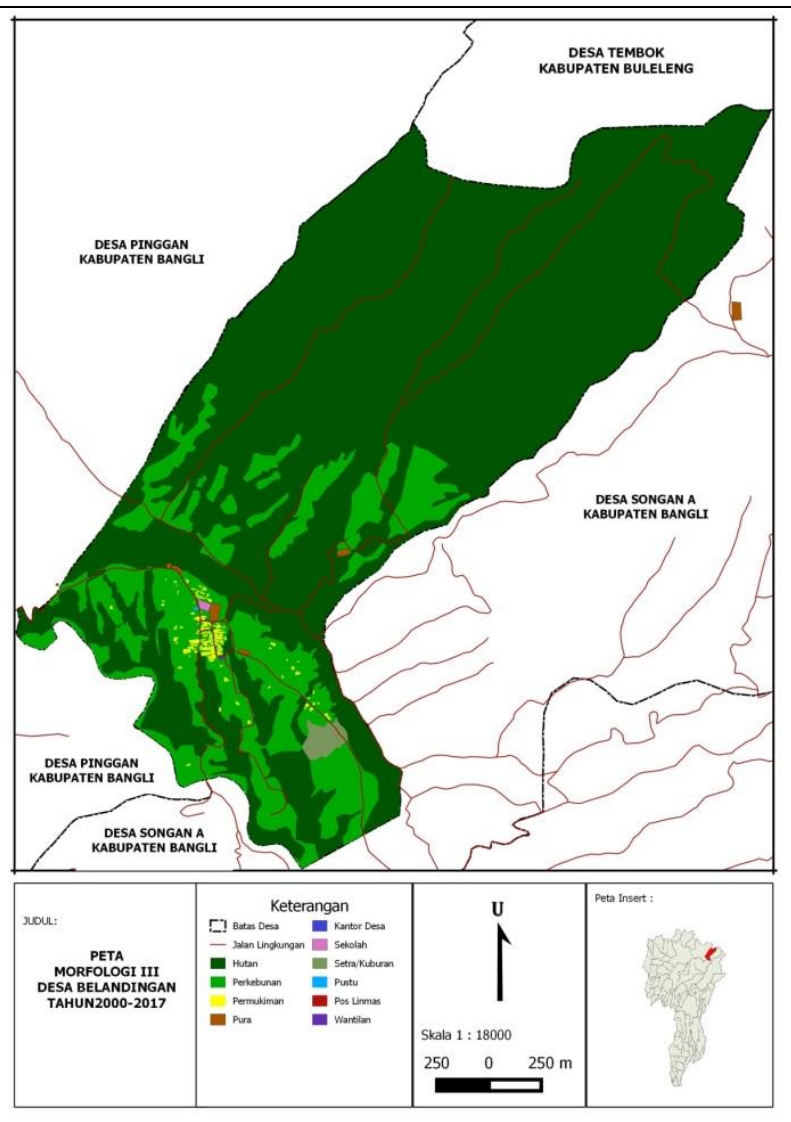

Gambar 8. Morfologi Ketiga Desa Belandingan Tahun 2000-2017

Sumber : Analisis, 2017

Perubahan juga dijumpai pada pola permukimannya, dimana tampaknya telah terjadi perubahan dengan adanya penambahan satu bangunan lagi dimasing-masing lahan milik $1 \mathrm{KK}$.
Namun perubahan tersebut sudah terjadi pada generasi ketiga diatasnya sehingga perubahan tersebut diterima saja oleh masyarakat sekarang.

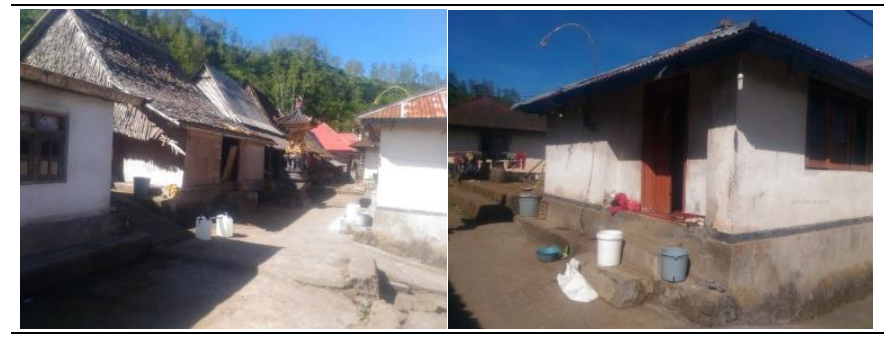

Gambar 9. Rumah "Modern" Berhadapan Dengan Ruamh Tradisional

Sumber: Dokumen Pribadi, 2017

Adanya pertambahan penduduk, menjadikan terjadinya pengembangan kawasan permukiman yakni permukiman di Banjaran Anyar sekitar tahun 1978 Permukiman di Banjaran Anyar memiliki luas sekitar 1 Hektar, memanfaatkan laba (tanah milik pura) dari Pura Bale Agung. Dalam mengembangkan permukiman di Banjaran Anyar ini, masyarakat percaya bahwa posisi bangunan tidak boleh berada lebih tinggi dari Pura Bale Agung. Sudah pernah ada penduduk yang membuat bangunan lebih tinggi dari pura, dan penduduk tersebut sering mengalami 'gangguan'. Pola permukiman di Banjar Anyar berbeda dengan permukiman di Desa Induknya sehingga terdapat pola baru di dalam pola lama. Tampaknya hal ini menjadi pertimbangan apabila akan membuka pola permukiman yang baru kembali karena harus mempertimbangkan pola yang akan digunakan apakah tetap mengacu pada pola yang yang lama ataukah pada pola yang baru seperti di Banjaran anyar atau bahkan membuat pola yang baru yang berbeda antara di Banjaran Anyar dan permukiman di Desa Induk.

Adanya program Bedah Rumah dari Pemerintah Provinsi Bali sejak tahun 2013-2017 sebanyak 27 unit serta bantuan stimulan perumahan swadaya tahun 2017 sebanyak 80 unit dari Kementerian PUPR memiliki andil dalam merubah tatanan pola tradisional yang ada. Perubahan tersebut cenderung merusak karena tidak mengindahkan pola ruang tradisional yang ada. Bentuk rumah-rumah bantuan tersebut sangat berbeda baik dari segi bentuk, bahan bangunan serta tata nilai yang ada. Dalam tata tradisional Belandingan, dimana pengaturannya menerapkan konsep rwa bhineda, yakni hulu teben secara jelas menjadi kacau karena bentuk baru yang disusupkan dalam konsep rumah tradisionalnya. Ada harapan dari masyarakat Belandingan sendiri, apabila mendapat bantuan perumahan kembali, diharapkan bantuan tersebut untuk mengembalikan ruamh-rumah tradisionalnya yang sulit dibangun kembali karena terbentur masalah dana.

Adanya satu unit bangunan 2 lantai milik salah seorang penduduk juga perlu untuk dibijaksanai agar tidak semakin menghilangkan ciri tradisional desa belandingan. 
Perubahan Pola Ruang Desa Bali Aga Belandingan Kintamani, Bali

Tabel 2 . Analisa Zona Tri Mandala Desa Belandingan

2. Karakteristik Pola ruang tradisional Desa

\begin{tabular}{|c|c|c|c|c|}
\hline No & $\begin{array}{l}\text { Zona Tri } \\
\text { Mandala }\end{array}$ & Ciri Khusus & Eksisting & Analisa \\
\hline 1 & $\begin{array}{ll}\text { Zona } & \text { Utama } \\
\text { Mandala } & \end{array}$ & $\begin{array}{l}\text { zona parahyangan ini di } \\
\text { fungsikan untuk } \\
\text { parahyangan dimana ciri } \\
\text { khas pada zona ini adalah } \\
\text { pura dan perbukitan (hutan) }\end{array}$ & $\begin{array}{l}\text { Pada perkembangannya pada Zona ini sudah terdapat } \\
\text { permukiman karena pengembangan permukiman baru di } \\
\text { banjaran anyar yang memanfaatkan lahan laba pura Bale } \\
\text { Agung . Pemanfaatan laba Pura Bale Agung sebagai } \\
\text { kawasan permukiman dan fasilitas desa membaurkan zona } \\
\text { utama mandala ini. Namun masih bisa ditolerir karena } \\
\text { tidak ada bangunan permukiman yang posisinya di atas } \\
\text { pura. }\end{array}$ & Tidak Sesuai \\
\hline 2 & $\begin{array}{ll}\text { Zona } & \text { Madya } \\
\text { Mandala } & \end{array}$ & $\begin{array}{lr}\text { Zona ini } & \text { sebagai } \\
\text { perwujudan } & \text { fungsi } \\
\text { pawongan dalam } & \text { Tri Hita } \\
\text { Karana sebagai zona untuk } \\
\text { berhubungan } & \text { sesame } \\
\text { manusia } & \end{array}$ & $\begin{array}{l}\text { Pada zona ini sepenuhnya difungsikan sebagai kawasan } \\
\text { permukiman . Namun program bedah rumah yang } \\
\text { dicanangkan telah merusak tatanan pola permukiman } \\
\text { tradisional Desa Belandingan }\end{array}$ & Sesuai \\
\hline 3 & $\begin{array}{ll}\text { Zona } & \text { Nista } \\
\text { Mandala } & \end{array}$ & $\begin{array}{l}\text { Pada zona ini sebagai } \\
\text { perwujudan dari fungsi } \\
\text { palemahan. Ciri yang khas } \\
\text { adalah keberadaan Setra } \\
\text { (Kuburan) }\end{array}$ & $\begin{array}{l}\text { Seperti di zona utama mandala, pada zona ini juga sudah } \\
\text { terdapat rumah-rumah penduduk yang dulunya merupakan } \\
\text { bangunan tidak permanen berubah menjadi bangunan } \\
\text { permanen dikarenakan tidak cukupnya lahan permukiman } \\
\text { di pusat desa. }\end{array}$ & Tidak Sesuai \\
\hline
\end{tabular}

Sumber: analisis, 2017

Mencontoh dari apa yang sudah terjadi di Desa Pengotan, dimana terdapat pembagian yang jelas antara permukiman lama dan permukiman di tegalan, yang mana bisa diterapkan di Desa Belandingan.

Perubahan pada skala mikro lainnya dijumpai pada pengaturan mandala pura. Dulunya pura tidak mengenal pembagian mandala seperti kondisi saat ini. Penempatan pelinggih pura biasanya ditempat yang lebih tinggi dari daerah sekitarnya seperti yang terlihat di Pura Puseh, Pura Bale Agung, Pura Dukuh, Pura Puseh ataupun Pura Sang Hyang Song. Hanya Pura Dalem, Pura Pemapagan dan Pura penegtegan yang berada dalam posisi yang cukup landai. Pura-pura dulunya juga tidak memilki penyengker (tembok pembatas).

Sekitar tahun 1980-an, dengan bertambahnya penduduk dan agar pura memiliki batas yang jelas, masyarakat memutuskan untuk membuat penataan pura dengan membuat penyengker pura. Pembuatan penyengker ini menjadikan pura memiliki jeroan dan jaba tengah/jaba sisi. Perubahan-perubahan yang terjadi di area pura sesungguhnya menuju kearah yang positif dimana hierarki mandala dari pura semakin terlihat. Namun perubahan tersebut tidak sama pada setiap pura karena menyesuaikan dengan kondisi topografinya. Kondisi topografi tersebut menjadikan pura di Belandingan menjadi unik.

\section{Kesimpulan}

Berdasarkan hasil temuan dan pembahasan sebelumnya, maka kesimpulan yang dapat diambil pada penelitian ini dapat dijabarkan sebagai berikut:

1. Pola ruang desa Belandingan banyak dipangaruhi oleh kondisi geografis kawasannya yang berada didaerah pegunungan. Hal ini sangat tampak dari perletakan posisi kawasan sucinya baik pura maupun merajan
Belandingan secara makro mengkuti konsep Tri Hita Karana dan Tri Mandala.

3. Pola ruang permukiman desa berbentuk linier mengikuti 2 sumbu utama desa yang menghubungkan blok-blok permukiman banjaran melalui gang-gang kecil sebagai aksesnya. Konsep yang digunakan pada pola permukimannya adalah konsep hulu teben

4. Perpindahan permukiman tidak serta merta membuat masyarakat desa juga memindahkan pura kahyangan tiganya yakni Pura Puseh kearah permukiman sekarang. Masyarakat Desa Belandingan memiliki ketaatan yang tinggi dalam mempertahankan keberadaan Posisi dari Purapura tersebut. Perubahan yang tampak pada pola ruang tempat suci (pura) nya adalah pembuatan 23 mandala baru

5. Perubahan terhadap pola ruang desa secara garis besar terbagi atas 3 periode yakni periode I tanpa angka tahun yakni perpindahan pusat permukiman dari Pura Puseh Meneng ke pusat pemukiman sekarang. Periode II (1975-2000) adalah penambahan fasilitas-fasilitas umum dan sosial masyarakat serta pemekaran wilayah permukiman dengan dibentuknya banjaran anyar dan Periode III adalah perubahan yang diakibatkan karena penyediaan fasilitas-fasilitas dalam kawasan permukiman serta perubahan terhadap pola permukiman tradisionalnya

6. Dalam perubahan-perubahan tersebut yakni pada periode III terjadi pengrusakan pola tradisional yang diakibatkan oleh bantuan dari pemerintah yakni program bedah rumah dari Pemerintah Provinsi Bali serta program bantuan Stimulan Perumahan Swadaya dari kementerian PUPR. Saat ini masyarakat mengharapkan bantuan dari pemerintah untuk memperbaiki rumah tradisionalnya. 


\section{Daftar Pustaka}

Dwijendra, Ngakan Ketut Acwin. 2003. Perumahan dan Permukiman Tradisional Bali. Jurnal Permukiman Natah Vol 1. No 1 Februari

Runa, I Wayan . 2018. Arsitektur Publik Bali Kuno Sistem Spasial Desa Pegunungan. Udayana University Press

Sukariyanto, I Gede Made. 2015. Partisipasi Masyarakat Lokal Dalam Pengembangan Desa Belandingan Sebagai Desa Wisata di Kabupaten Bangli. Sekolah Tinggi Pariwisata Bali. Diunduh dari https://www.scribd.com/doc/282463049/Partisipasi -Masyarakat-Lokal-Dalam-Pengembangan-DesaBelandingan-Sebagai-Desa-Wisata-Di-KabupatenBangli, tanggal 29 mei 2016. 